\title{
Participação social e gestão ambiental: uma análise do conselho gestor do Parque Estadual da Serra do Brigadeiro, Minas Gerais - Brasil
}

\author{
Social participation and environmental management: an analysis of the \\ managing council at Serra do Brigadeiro State Park, Minas Gerais - Brazil
}

\begin{abstract}
Resumo
O processo de redemocratização brasileiro engendrou diversas experiências de gestão participativa em distintos setores. Na esfera ambiental, por exemplo, a criação de conselhos gestores de Unidades de Conservação (UC) foi uma destas experiências que trouxe avanço político e social no que conserne à sustentabilidade e à gestão democrática destes territórios. Nesse contexto, o artigo analisa a constituição e o funcionamento de um conselho gestor de uma UC no estado de Minas Gerais que é tido como um dos mais participatidos, qual seja: o conselho consultivo do Parque Estadual da Serra do Brigadeiro (PESB). Operacionalizamos metodologicamente o trabalho com a observação participante nas reuniões deste conselho e com análises documentais. Como resultados, argumentamos que um dos elementos que fazem com que o conselho do PESB seja participativo diz respeito ao próprio processo de implementação desta UC, primeira de Minas Gerais criada de forma participativa; e que a existência prévia de processos mobilizatórios na região levaram ao envolvendo da sociedade civil na construção e implementação do conselho consultivo do PESB, estruturando o mesmo em termos de representatividade e paridade política. Evidentemente que isso não se deu sem conflitos, mas, de maneira geral, argumentamos que este conselho tem garantindo a pluralidade social no que tange à representação da sociedade civil e assegurando processos democráticos na gestão ambiental.
\end{abstract}

Palavras-chave: Gestão ambiental. Participação social. Unidade de conservação.

\begin{abstract}
The Brazilian redemocratization process has generated several participatory management experiences in different sectors. In the environmental sphere, for example, the creation of management councils of Conservation Units (UC - Unidades de Conservação) was one of those experiences that brought political and social progress in what concerns the sustainability and democratic management of these territories. In this context, the article analyzes the constitution and functioning of a managing council of a UC in the state of Minas Gerais, considered one of the most participative, namely: the Advisory Council of the Serra do Brigadeiro State Park (PESB - Parque Estadual da Serra do Brigadeiro ). We work methodologically with participant
\end{abstract}

${ }^{1}$ Instituto Federal de Educação, Ciência e Tecnologia do Sudeste de Minas Gerais (IF Sudeste MG), Muriaé, Minas Gerais, Brasil. Email: lucas.magno@ifsudestemg.edu.br 
observation and with document reviews. As results, we argue that one of the elements that make the Council of the PESB participatory is the process of implementation of this UC itself, the first of Minas Gerais created in a participatory manner; and that the prior existence of mobilization processes in the region led to the involvement of civil society in the construction and implementation of its Advisory Council, structuring it in terms of representativeness and political parity. Obviously this did not happen without conflicts, but, in general, we argue that this council has guaranteed social plurality with regard to the representation of civil society and ensuring democratic processes in environmental management.

Keywords: Environmental Stewardship. Social Engagement. Preservational Units.

\section{Introdução}

A década de 1980 no Brasil foi marcada por lutas sociais para conquistar espaços de participação da sociedade civil. Tais lutas estiveram associadas às capacidades que os movimentos sociais tiveram para explicitar demandas relativas a distribuição de bens e políticas públicas no período de redemocratização (AVRITZER, 2002; DAGNINO, 2002). Especificamente no que se refere à gestão ambiental, foi institucionalizada a tese, na Constituição Federal de 1988, de que a participação social contribuiria para sustentabilidade e para a repartição equitativa dos benefícios da utilização dos recursos naturais. Esta tese foi reafirmada na década de 1990, a partir da Conferência das Nações Unidas sobre Meio Ambiente e Desenvolvimento, na qual compromissos que envolviam a inclusão social na questão ambiental foram assumidos por diversos governos (JACOBI, 2000; MACHADO et al., 2012).

Anos mais tarde, a promulgação da Lei $\mathrm{n}^{\mathrm{o}}$ 9.985/2000 (BRASIL, 2000), que criou o
Sistema Nacional de Unidades de Conservação (SNUC), assegurou a participação efetiva das populações na criação, implantação e gestão de Unidades de Conservação (UC) no Brasil. Nesse contexto, a criação de conselhos gestores em UC foi uma das novidades na gestão ambiental nas últimas décadas, tanto em nível federal quanto nas áreas protegidas estaduais e municipais (LOUREIRO; CUNHA, 2008; MACHADO et al., 2012).

Tendo caráter interinstitucional e de inclusão da sociedade civil nas decisões, os conselhos gestores de UC no Brasil têm papel importante de mediação entre a sociedade e o Estado. Segundo Lüchmann (2011), diferente de outras modalidades de representação política, a representação em conselhos gestores ocorre por meio de organizações sociais que dividem o espaço com atores estatais e que têm atribuição de representar os cidadãos na formulação de políticas públicas ou no direcionamento de recursos. Assim, a participação da sociedade civil na gestão ambiental introduz uma (re)organização 
política significativa, uma vez que incorporam outros níveis de poder no ordenamento territorial para além do Estado e de aspectos meramente técnicos (JACOBI, 2003; 2006; JACOBI; BARBI, 2007).

Tendo esse debate como pressuposto, o artigo analisa a constituição e o funcionamento do conselho consultivo do Parque Estadual da Serra do Brigadeiro (PESB), UC localizada na região da Zona da Mata mineira. O Institudo Esdatual de Florestas (IEF), autarquia responsável pela gestão das áreas protegidas de Minas Gerais, com representação neste conselho, já apresentou o conselho em atuação no PESB como o mais participativo do estado. De tal modo, questiona-se: quais razões levaram o conselho do PESB a ser considerado um dos conselhos gestores de UC mais participativos de Minas Gerais?

O trabalho empregou a observação participante nas reuniões do conselho consultivo do PESB entre 2016 e 2018 e a análise documental do edital de eleição, do regimento interno e da portaria de designação do conselho (MINAS GERAIS, 2015; 2016a; 2016b), além de levantamentos de literatura especializada sobre a criação do PESB.

\section{A criação do Parque Estadual da Serra do Brigadeiro: conflitos ambientais, mobilização social e resistência}

A criação de UC tem sido uma das principais estratégias territoriais de conservação da natureza no Brasil. De acordo com Diegues (2001), a legislação brasileira, que criou os parques e as reservas ambientais, seguiu o modelo preservacionista norteamericano que resultava no deslocamento ou expulsão dos moradores dessas áreas, causando uma série de problemas éticos, sociais, econômicos, políticos e culturais; e a proposta inicial de criação do Parque Estadual da Serra do Brigadeiro (PESB) pretendia seguir essa perspectiva de "natureza sem gente".

Bonfim (2006) destacou que, desde a década de 1960, professores e técnicos da Escola de Florestas de Viçosa, atualmente Departamento de Engenharia Florestal da Universidade Federal de Viçosa (DEF/UFV), realizaram uma série de visitas à Serra do Brigadeiro para fins científicos. Nesse período, a preocupação em preservar o que viria a ser um dos últimos remanescentes de mata atlântica do estado de Minas Gerais culminou com tratativas para a criação de uma UC no local. Assim, ainda segundo Bonfim, em 1962 foi assinado o Decreto Estadual $n^{0} 1.493$, que declarou de interesse ambiental as florestas nativas existentes naquela região, especialmente as localizadas em propriedades rurais.

Já na década de 1970, pesquisadores do DEF/UFV chegaram à conclusão de que a solução mais racional para preservar aquele importante fragmento florestal era a criação de uma UC (COUTO; DIETZ, 1980). Foi nesse contexto que uma proposta inicial de limites para a criação do PESB foi feita, considerando 
necessário preservar 32.500 hectares a partir da cota de 1.000 metros de altitude.

$\mathrm{Na}$ teoria, seguindo os preceitos preservacionistas, isso seria um avanço, já que uma extensa área de mata atlântica na Zona da Mata mineira seria destinada para fins exclusivos de preservação, turismo ambiental e pesquisa científica. $\mathrm{Na}$ prática, porém, isso colocaria milhares de agricultores familiares residentes em nove municípios (a saber: Araponga, Ervália, Rosário da Limeira, Muriaé, Miradouro, Fervedouro, Divino, Sericita e Pedra Bonita) em situação de vulnerabilidade social, já que os mesmos teriam que ser retirados do local para dar lugar a uma UC.

Segundo Bonfim (2006), na época de realização dos estudos ambientais para a criação do parque não foi previsto esse problema fundiário, uma vez que os levantamentos feitos junto à Fundação Rural Mineira (RURALMINAS) apontaram que 60\% da área era composta de terras devolutas. Estes dados, no entanto, foram contestados por agricultores, pois, para eles, a RURALMINAS considerou terra devoluta todas as áreas em que os proprietários não têm o título regular e na região da Zona da Mata mineira existem muitas situações como esta.

Desconsiderando essa inconsistência nas pesquisas ambientais, em 1988 o governo de Minas Gerais publicou a Lei $\mathrm{n}^{0} 9.655$ que autorizava a criação do PESB e a desapropriação de inúmeras famílias de agricultores da área. Nesse contexto, em 1993 o Instituto Estadual de Florestas (IEF) contratou profissionais ligados à Universidade do Estado de Minas Gerais (UEMG), à UFV e uma empresa de consultoria ambiental para realização de estudos do meio físico para a implementação do PESB (BONFIM, 2006).

No mesmo período, o Centro de Tecnologias Alternativas da Zona da Mata (CTA), Organização Não-governamental com atuação na região em processos de transição agroecológica, realizava, junto com o Sindicato dos Trabalhadores Rurais (STR) de Araponga, um Diagnóstico Rural Participativo (DRP) para traçar o perfil de atuação desta organização na região. E entre as demandas que foram diagnosticadas pelo CTA uma apareceu de forma recorrente, qual seja: a preocupação com a criação do parque e o deslocamento de agricultores. Segundo Praça (2010), foi com esse DRP que se visibilizou uma disputa territorial na Serra do Brigadeiro, pois foi quando atores da sociedade civil manifestaram insatisfação e se apropriaram de instrumentos formais para adentrar em uma seara político-ambiental que afetaria diretamente suas vidas.

Assim, dois processos sociais na região têm início e eles estavam relacionados com a criação da UC, a saber: i) a identificação de um conflito ambiental (ACSELRAD, 2004) envolvendo agricultores familiares e órgãos gestores do meio ambiente no estado de Minas Gerais; e ii) o início de uma mobilização social que queria mudanças no critério de demarcação da área do PESB. A esses dois processos, além do CTA e STR de Araponga, se juntaram também os STR dos outros 
municípios que seriam afetados com a criação do PESB, a Comissão Pastoral da Terra (CPT), a Federação dos Trabalhadores na Agricultura do Estado de Minas Gerais (FETAEMG), alunos e professores da UFV e organizações religiosas, sobretudo as ligadas às Comunidades Eclesiais de Base (CEBS) da Igreja Católica (BONFIM, 2006; PRAÇA, 2010; OLIVEIRA, 2015).

A partir daí uma série de reuniões com os atores sociais envolvidos no conflito ambiental foram realizadas, grupos de trabalhos com representantes de órgãos governamentais e organizações da sociedade civil foram criados e seminários abertos ao público foram construídos no CTA e na UFV. Importa destacar que com isso as informações que antes eram restritas apenas aos técnicos do IEF se tornaram de domínio público, pesquisas com propostas alternativas de criação do PESB foram apresentadas e debates envolvendo a Assembleia Legislativa do Estado de Minas Gerais (ALEMG) foram realizados; e, assim, a proposta inicial de criação do parque foi sendo repensada.

Nesse contexto, em 1996 o governo de Minas Gerais, apoiando-se em relatorias do IEF das reuniões, grupos de trabalhos, seminários e audiências realizadas para debater a construção do parque, revisou o ato de criação do PESB, publicando o Decreto Estadual no 38.319 (MINAS GERAIS, 1996). Neste decreto a área inicial de 32.500 hectares foi reduzida para 13.210 hectares, considerando os aspectos ambientais, sociais, econômicos e a participação política como elementos importantes para a redefinição dos limites do parque (BONFIM, 2006). Com isso, o deslocamente de agricultores posto com a proposta inicial havia sido descartado, configurando uma vitória popular no que tange a delimitação desta UC.

Porém, após a (re)definição do parque com os seus novos limites pelos órgãos ambientais de Minas Gerais, em 2002 tem início nova seara na região, desta vez envolvendo a construção do plano de manejo do PESB. Tal como os encaminhamentos metodológicos relativos à criação do parque, a proposta de construção do plano de manejo envolveu a formação de um grupo de trabalho com participação de atores governamentais e sociedade civil que passou a ser denominado Colegiado do PESB (BONFIM, 2006).

Em 2003 o Colegiado do PESB realizou audiência com o IEF e a Secretaria de Meio Ambiente e Desenvolvimento Sustentável de Minas Gerais (SEMAD) para apresentação do processo histórico de criação do parque e para reafirmar a importância de o plano de manejo ser feito de forma participativa. Como resultado, a SEMAD e o IEF firmaram o compromisso público de construir um Conselho Consultivo com representação de órgãos governamentais e sociedade civil, marcando nova vitória popular; e em 17 de fevereiro de 2004, através da Portaria $\mathrm{n}^{0} 021$ do IEF, o Conselho Consultivo do PESB foi instituído (MINAS GERAIS, 2004).

É importante frisar que o processo de construção do PESB foi reflexo de conflitos ambientais, mobilizações sociais e de 
resistência a propostas meramente técnicas e exógenas ao território. Portanto, argumenta-se que, embora influenciada por demandas legais ou regulamentada por decretos, a criação do PESB de forma participativa foi mais um processo que refletiu o comprometimento histórico das organizações sociais atuantes na Serra do Brigadeiro com o desenvolvimento sustentável e a inclusão social. Nesse sentido, ainda quedurante toda a década de 1990 houvesse debates ambientais sobre participação social na criação e gestão de UC no Brasil, o caso apresentado mostra que estes debates tiveram menos peso na criação do PESB do que a mobilização popular. E isso, a nosso ver, é um dos elementos que pode explicar a intensa participação de atores governamentais e da sociedade civil no seu conselho consultivo atualmente.

Com essa afirmação não estamos querendo dizer que leis, a exemplo da Lei $\mathrm{n}^{\circ}$ 9.985/2000 (BRASIL, 2000), e decretos, tal como o Decreto $\mathrm{n}^{\circ}$ 4.340/2002 (BRASIL, 2002), não tiveram influência na construção do PESB e, posteriormente, do seu conselho consultivo. Tais instrumentos legais, em maior ou menor grau, foram frutos de debates que envolviam a sociedade civil no âmbito macro político. Eles, sem dúvida, são instrumentos relevantes para a inclusão social na gestão ambiental de UC no país, tal como a literatura tem apontado (JACOBI, 2000; 2006; JACOBI; BARBI, 2007; LOUREIRO; CUNHA, 2008). Porém, o que estamos querendo argumentar é que na Zona da Mata mineira já existiam processos sociais, ambientais e culturais, a exemplo dos relativos à transição agroecológica encampados pelo CTA e STR desde a década de 1980 e os relacionados às CEBS da Igreja Católica, que foram importantes na implantação do PESB; e isso teve tão ou mais relevância na implementação desta UC que os instrumentos legais.

Por isso que, em consonância com o que argumentaram Becker (2009) e Guerra e Coelho (2009), afirmamos que para se criar uma UC ou para realizar uma gestão condizente com os objetivos da preservação ambiental é preciso levar em consideração sua localização e as formas de usos e apropriações espaciais, nas quais se inserem as relações sociais, uma vez que, como qualquer outro território, as UC constituem-se formas complexas de relações entre sociedade e território.

\section{O conselho consultivo do PESB: organização, funcionamento $\mathrm{e}$ composição}

O conselho consultivo do PESB foi formalmente instituído em 2004 e composto, inicialmente, por representantes das organizações sociais e órgãos públicos envolvidas nos debates e processos relacionados à criação desta UC, entre eles CTA, STR, UFV, prefeituras municipais, polícia ambiental, dentre outras organizações sociais e representantes dos moradores do entorno do parque. Entretanto, foram muitos erros e atropelos da gestão em relação à operacionalização inicial deste conselho, 
gerando insatisfação em muitas ocasiões. Foi então que, entre os anos de 2004 e 2005, várias ações foram construídas pelos conselheiros a fim de (re)organizar a gestão desta UC e, entre elas, estava a elaboração do seu regimento interno (BONFIM, 2006).

Para a construção desse documento interessava aos conselheiros resguardar os processos socioambientais da Serra do Brigadeiro, principalmente os relativos à representatividade das organizações sociais envolvidas na criação do PESB, e seguir as normatizações legais, sobretudo o Decreto Estadual n ${ }^{\circ} 45.834 / 2011$, que regulamentou as ações do IEF em relação à gestão de áreas protegidas em Minas Gerais, a Lei $n^{\circ}$ 9.985/2000 e o Decreto Federal n ${ }^{\circ} 4.340 / 2002$. Tendo isso como pressuposto, a finalidade e as competências do conselho consultivo do PESB foram definidas, entendendo que ele deveria

Art. $3^{\circ}-(\ldots)$ auxiliar o Órgão Gestor da Unidade de Conservação na nobre tarefa de implementá-la, competindo-lhe propor diretrizes, políticas, normas regulamentares e técnicas, padrões e demais medidas de caráter operacional para a preservação e conservação do meio ambiente e dos recursos ambientais característicos da Unidade de Conservação e de sua Zona de Amortecimento (MINAS GERAIS, 2015, p.1).

Em termos de organização desse conselho, o regimento colocou a necessidade de o mesmo ter a seguinte estrutura: i) presidência; ii) plenário; iii) secretaria executiva; e vi) grupos de trabalho. A presidência do conselho é exercida pelo gerente da UC, indicado pelo IEF nos termos do Decreto Federal $\mathrm{n}^{\mathrm{o}} 4.340 / 2002$, e a ela compete, dentre outras coisas, submeter matérias a serem analisadas pelo conselho e cumprir e fazer cumprir suas decisões, e promover a articulação do conselho com órgãos e entidade integrantes do Sistema Estadual de Meio Ambiente (SISEMA).

Ao plenário, instância superior do conselho do PESB, cabe, dentre outras ações: a) acompanhar a elaboração, a implementação e a revisão do plano de manejo da UC, garantindo o seu caráter participativo; b) buscar a integração da UC com as demais territórios protegidos e com o seu entorno; c) compatibilizar os interesses dos diversos segmentos sociais relacionados com o PESB; d) avaliar o orçamento da unidade e o seu relatório financeiro; e) manifestar-se sobre obra ou atividade potencialmente causadora de impacto na UC, em sua zona de amortecimento, mosaicos ou corredores ecológicos; f) propor diretrizes e ações que compatibilizem, integrem e otimizem a relação com a população do entorno; g) estabelecer orientações sobre políticas e ações de proteção, conservação e melhoria do meio ambiente da UC e de sua Zona de Amortecimento; e h) solicitar à presidência assessoramento de instituições públicas (MINAS GERAIS, 2015).

À secretaria executiva cabe apoiar a operacionalização administrativa do conselho. E, por fim, aos grupos de trabalho compete: a) elaborar, implementar, acompanhar e revisar o plano de manejo; b) debater os usos públicos do território da UC; c) propor diretrizes para a 
zona de amortecimento do PESB; d) propor ações de educação ambiental com a comunidade do entorno; e) tomar conhecimento e realizar pesquisas; e f) elaborar plano de trabalho para ações de compensação ambiental (MINAS GERAIS, 2015).

Cabe destacar que, conforme regulamento interno, na estrutura do conselho do PESB tem maior relevância e abrangência de ações o plenário, isto é, os conselheiros propriamente ditos. Isso mostra a preocupação do mesmo com as deliberações relativas à gestão desta UC e com a paridade política; e embora o conselho seja consultivo, é consenso entre os conselheiros e presidência que as decisões do plenário sejam respeitadas. Com isso, as propostas, seja elas de um morador do entorno sem conhecimentos técnicos, seja as de um profissional especialista, têm a mesma representatividade política.

Esse apontamento, em certa medida, contraria algumas indicações feitas pela literatura relativa à gestão participativa em conselhos gestores no Brasil (TATAGIBA, 2002; JACOBI, 2000; 2006). Porém, isso não pode ser considerado como regra, já que é importante resguardar as especificidades dos processos de constituição do PESB que tiveram grande influência na estruturação desse conselho e no seu regimento interno.

Em relação ao funcionamento do conselho do PESB, este se dá a partir de reuniões públicas ordinárias trimestrais (de acordo com calendário previamente estabelecido) e de encontros extraordinários, convocados pelo presidente ou por maioria absoluta de seus membros sempre que houver assuntos de relevante interesse. Em todas as reuniões, que se dão de forma itinerante (ora na sede do PESB, ora nos municípios vizinhos) é necessário observação de quórum (maioria absoluta) para que a mesma tenha início.

A composição do conselho é feita através de publicação de edital de eleição pelo IEF, tendo os conselheiros eleitos mandato de dois anos prorrogáveis por igual período. Para garantir equidade de participação de diversos órgãos públicos (federais, estaduais e municipais), organizações sociais (e.g. ONG, STR, Igreja, etc.) de diferentes áreas (educação, ciência, segurança pública, cultura, turismo, arquitetura, povos tradicionais, dentre outros) o edital prevê a eleição de 36 membros (18 titulares e 18 suplentes), sendo as vagas distribuídas da seguinte forma: oito representantes de órgãos públicos ambientais das esferas federal, estadual e municipal; quatro representantes de secretrais de segurança pública e defesa social de Minas Gerais; quatro de órgaõs públicos de educação das esferas federal, estadual e municipal atuantes na região de abrangência da UC; dois de comunidades científicas atuantes na área do PESB; quatro de ONG socioambientais atuantes no entorno da UC; dois do setor privado; dois representantes de empresas públicas e/ou de concessionárias de serviços públicos ou, ainda, de sociedade de economia mista; dois de STR ou de associações comunitárias da região; quatro de comitês de bacias hidrográficas e/ou associações de 
circuitos turísticos; e seis representantes da população local (MINAS GERAIS, 2016a).

A atividade de conselheiro se dá de forma voluntária e se constitui de interesse público, não gerando vínculo empregatício de nenhuma natureza. Porém, como há diferentes órgãos e organizações que podem ter interesses conflitantes em relação às suas áreas de atuação na região, o membro do conselho é impedido de atuar quando: a) tenha interesse direto ou indireto na matéria em discussão; b) tenha vínculo jurídico, empregatício ou contratual com pessoa física ou jurídica envolvida na matéria; c) tenha participado como perito, testemunha ou representante, ou cujo cônjuge, companheiro ou parente esteja em uma dessas situações; e d) esteja em litígio judicial ou administrativo com o interessado (MINAS GERAIS, 2016a).

Nesse contexto, atualmente o conselho consultivo do PESB é composto pelos seguintes órgãos públicos e entidades da sociedade civil (MINAS GERAIS, 2016b):

a) Prefeitura Municipal de Fervedouro;

b) Prefeitura Municipal de Pedra Bonita;

c) Instituto Estadual de Florestas;

d) Prefeitura Municipal de Araponga;

e) Corpo de Bombeiros Militar de Minas Gerais;

f) Instituto Federal de Educação, Ciência e Tecnologia do Sudeste de Minas Gerais Campus Muriaé;

g) Prefeitura Municipal de Rosário da Limeira;

h) Prefeitura Municipal de Muriaé;

i) Prefeitura Municipal de Miradouro; j) Associação Amigos de Iracambi;

l) Centro de Tecnologias Alternativas da Zona da Mata;

m) Associação Escola Família Agrícola de Ervália;

n) Sindicato dos Trabalhadores Rurais de Muriaé, Barão de Monte Alto e Rosário da Limeira;

o) Associação do Circuito Turístico Serras de Minas;

p) Companhia Brasileira de Alumínio; e

q) Associação Franciscana de Santa Maria dos Anjos.

Ressalta-se que as vagas destinadas à população local não foram preenchidas no biênio 2016-2018.

De modo geral, pode-se afirmar que a composição do plenário do conselho do PESB é ampla, ou seja, abrange diversas representações de órgãos públicos em diferentes esferas de governo e de distintos setores, de organizações sociais ligadas à esfera trabalhista, segmentos religiosos, empresa de mineração e também representantes de movimentos ambientalistas. Assim, ele, por um lado, contempla aspectos relacionados à democracia representativa, e, por outro lado, encerra questões relativas à democracia deliberativa, dando caráter plural e colegiado às decisões. Contudo, além destes aspectos, a participação na gestão do PESB também está relacionada com o grau de conhecimento desta UC pelos seus conselheiros que, em sua maioria, têm ciência ou vivenciaram o processo conflituoso de sua constituição. 
Tal pluralidade de representação e o próprio conhecimento histórico sobre o processo de criação do PESB certamente facilitam as deliberações de determinadas matérias, mas, em contrapartida, conforme alertaram Tatagiba (2002) e Lüchmann (2011), isso não exclui a possibilidade de existência de clivagens ou relações de clientelismo, paternalismo e de trocas econômicas e políticas no campo das organizações sociais e do Estado que levam a tensionar o ideal de paridade e representatividade, uma vez que a sociedade civil é uma esfera repleta de diferenças, contradições, conflitos e desigualdades sociais; e que a paridade numérica não necessariamente corresponde a paridade política.

Tal alerta é oportuno, uma vez que, no entorno do PESB existem dezenas de áreas de ocorrência de bauxita concedidas à Companhia Brasileira de Alumínio (SILVA, 2012; MAGNO et al., 2017) e esta empresa faz parte do conselho do parque como um dos representantes do setor privado; e conforme pontuaram Jacobi (2006), Jacobi e Barbi (2007) e Loureiro e Cunha (2008), nos conselhos estão inscritos intencionalidades dos atores que os compõem e isso norteia suas práticas gestionárias. Além disso, não é demais ressaltar que a existência de discrepâncias econômicas e políticas entre conselheiros podem valorizar excessivamente o poder de alguns atores em detrimento de outros em certas decisões (BIDERMAN FURRIELA, 2002). Por isso que a participação qualificada, principalmente de movimentos sociais, assume papel relevante na denúncia de contradições entre interesses privados e públicos nos conselhos gestores de UC.

Por fim, cabe indicar ainda que a construção do conselho consultivo do PESB, seja em termos de seu regimento interno, seja no que tange à sua representatividade social, é um processo inovador. Argumentamos que ele acabou rompendo com práticas arraigadas no país, de um modo geral, e em Minas Gerais especificamente, particularmente às relativas ao paternalismo e clientelismo, e isso acabou por delegar ao povo e suas organizações representativas 0 poder para a institucionalização de determinadas searas políticas e ambientais na região da Zona da Mata mineira. Isso, com efeito, contribui para que o conselho do PESB seja tido como um dos mais participativos do estado pelos órgãos ambientais.

\section{Considerações Finais}

Ao introduzir esse texto indicamos que as formas de participação da sociedade civil em canais e mecanismos de relação com o Estado foram ampliadas nas últimas décadas. Com ou sem o suporte de formas de representação política tradicional, elas têm sido caracterizadas pela literatura como democráticas e participativas e que abrem a esfera pública ao debate.

Especificamente em relação à gestão ambiental, vimos que o processo institucional brasileiro apresentou evolução nos últimos anos, engendrando a construção de conselhos 
gestores em UC e em outras formas de administração dos recursos naturais através da publicação de atos normativos legais. A participação social nestas instâncias se enquadra em processos de redefinições políticas entre o público e o privado, entre o particular e o coletivo e, principalmente, entre o Estado e a sociedade. Embora ainda consideradas complexas e desiguais, tais formas de gestão ambiental participativas revelam a criação de condições para que se multipliquem experiências democráticas no país, e o caso da constituição do PESB e de seu conselho consultivo, a nosso ver, representa isso muito bem.

A criação do PESB e, posteriormente, de seu conselho consultivo reforçam o significado e a importância da participação em processos de (re)ordenamento territorial e de estabelecimento de espaços públicos decisórios, além de evidenciarem a complexidade envolvida na gestão de uma área protegida na Zona da Mata mineira. Isso, evidentemente, não se deu sem conflitos, mas, também, só ocorreu pelo fato de os técnicos e especialistas terem conseguido superar as assimetrias de poder, conhecimento e informações existentes entre diferentes atores sociais e pelo reconhecimento de outros espaços de debates, pesquisas contestatórias e audiências públicas conduzidos, fundamentalmente, pela sociedade civil.

Como indicamos, esse processo contraria algumas pesquisas que mostram que os conselhos gestores, que deveriam favorecer a interação e encontros entre sociedade e
Estado, terem sido afetados de forma negativa por causa de uma recusa de o Estado partilhar o seu poder nas tomadas de decisões ou pela existência de assimetrias de poder econômico e político (TATAGIBA, 2002; LÜCHMANN, 2011). Isso, sem dúvida alguma, não pode ser desconsiderado em análises posteriores, servindo, inclusive, de alerta para o próprio conselho do PESB na condução de suas decisões.

O caso analisado mostrou também possibilidades, avanços e conquistas políticas e sociais em gestão ambiental de UC, porém, não queremos com isso afirmar que ele seria ideal ou um modelo a ser seguido. Cada UC no país tem suas especificidades e desafios que devem ser consideradas por órgãos públicos e organizações sociais em suas peculiaridades. Mesmo no conselho do PESB ainda há questões que mercerem pesquisas posteriores, a exemplo da dimensão conflituosa inerente a um conselho em que uma mineradora com interesses minerários no entorno da UC tem uma cadeira no plenário.

Outro ponto que merece novas pesquisas e pode se colocar como desafio ao funcionamento do conselho do PESB, particularmente, e de outros conselhos de UC Brasil, de modo geral, diz respeito ao seu financiamento. Em relação a isso, atualmente não existe, no âmbito do IEF ou da SEMAD, uma política específica. Porém, manter o conselho ativo, em maior ou menor grau, exige manutenção de equipamentos e recursos para a realização de cursos, seminários e eventos em geral. Então, para se valorizar este espaço 
de debate é importante compreender as necessidades para sua viabilização. Nesse sentido, é fundamental que os gestores e os próprios conselheiros não aceitem financiamento privado de empresas que, por ventura, tenham interesse em realizar atividades potencialmente poluidoras para não privatizar a política ambiental em Minas Gerais (MILANEZ et al., 2018; MILANEZ et al., 2019; MILANEZ; MAGNO; PINTO, 2019).

De todo modo, acreditamos que o conselho do PESB concretiza preceitos de uma democracia deliberativa, assegurando a pluralidade de representação social em seu plenário (não sem conflitos!) e publicizando e orientando a sociedade civil e a população de forma geral a participarem da sua gestão. Para pesquisas posteriores destacamos ainda a necessidade de investigar as estratégias deste conselho em incorporar debates para o seu fortalecimento perante a sociedade, uma vez que, diante do atual contexto político brasileiro que indica mudanças na área ambiental, o desenvolvimento de estratégias de mobilização da opinião pública representa um elemento essencial para o êxito e continuidade de uma gestão que se quer participativa.

\section{Agradecimentos}

Agradeço ao IF Sudeste MG pelo apoio para a realização desse trabalho.

\section{Referências}

ACSELRAD, H. As práticas espaciais e o campo dos conflitos ambientais. In: ACSELRAD, $\mathrm{H}$. (Org.). Conflitos Ambientais no Brasil. Rio de Janeiro: Relume Dumará/Fundação Heinrich Böll, 2004. p. 13-35.

AVRITZER, L. Democracy and the Public Space in Latin America. New Jersey: Princeton University Press, 2002.

BECKER, B. Prefácio. In: GUERRA, A. J. T; COELHO, M. C. N. (orgs). Unidades de Conservação: abordagens e características geográficas. Rio de Janeiro: Bertrand Brasil, 2009. 17-19.

BIDERMAN FURRIELA, R. Democracia, cidadania e proteção do meio ambiente. São Paulo: Annablume, 2002.

BONFIM, V. R. Conflitos, participação e lições aprendidas no processo de criação do Parque Estadual da Serra do Brigadeiro (PESB), MG. Tese (Doutorado em Ciência Florestal), 166f. Universidade Federal de Viçosa, Viçosa-MG, 2006.

BRASIL. Ministério do Meio Ambiente. Decreto $n^{\circ} 4.340$, de 22 de agosto de 2002 . Regulamenta os artigos da Lei $n^{\circ}$ 9.985, de 18 de julho de 2000, que dispõe sobre o Sistema Nacional de Unidades de Conservação da Natureza - SNUC, e dá outras providências. Brasília-DF, 2002. Disponível

em: http://www2.mma.gov.br/port/conama/legiabr e.cfm?codlegi=374. Acesso em 20 de janeiro de 2019.

BRASIL. Ministério do Meio Ambiente. Lei $\mathbf{n}^{\mathbf{o}}$ 9.985, de 18 de julho de 2000 . Regulamenta o art. $225, \S 1^{\circ}$ incisos I, II, III e VII da Constituição Federal, institui o Sistema Nacional de Unidades de Conservação da Natureza e dá outras providências. Brasília-DF, 2000. Disponível em:

http://www.planalto.gov.br/ccivil_03/LEIS/L99 85.htm. Acesso em 20 de janeiro de 2019.

COUTO, E. A; DIETZ, J. M. Sugestões para elaboração do Parque Nacional da Serra do Brigadeiro. Viçosa: UFV, 1980. 27p. (Mimeo.)

DAGNINO, E. Sociedade civil, espaços públicos e a construção democrática no Brasil: limites e possibilidades. In: DAGNINO, E. (Org.). Sociedade civil e espaços públicos no Brasil. Paz e Terra: São Paulo, 2002, p. 279301.

DIEGUES, A. C. S. O mito moderno da natureza intocada. $3^{\circ}$ Ed. São Paulo: Hucitec/Núcleo de Apoio à Pesquisa sobre 
Populações Humanas e Áreas Úmidas Brasileiras/USP. 2001.

GUERRA, A. J. T; COELHO, M. C. N. (orgs). Unidades de Conservação: abordagens e características geográficas. Rio de Janeiro: Bertrand Brasil, 2009. 67-111.

JACOBI, P. R. Políticas sociais e ampliação da cidadania. Rio de Janeiro: Editora FGV, 2000.

JACOBI, P. R. Espaços públicos e práticas participativas na gestão do meio ambiente no Brasil. Sociedade e Estado, UnB, Brasília, v. $18, \quad$ n. $1 / 2, \quad 2003$. https://doi.org/10.1590/S010269922003000100015

JACOBI, P. R. Participação na gestão ambiental no Brasil: os comitês de bacias hidrográficas e o desafio do fortalecimento de espaços públicos colegiados. ALIMONDA, H. (Org.). Los tormentos de la materia. Aportes para una ecología política latinoamericana. ALIMONDA, $\mathrm{H}$. CLACSO, Consejo Latinoamericano de Ciencias Sociales, Buenos Aires. Marzo 2006. p. 37-2.

JACOBI, P. R; BARBI, F. Democracia e participação na gestão de recursos hídricos no Brasil. Revista Katálysis. v. 10, n. 2, jul/dez, 2007. p.

$237-244$

https://doi.org/10.1590/S141449802007000200012

LOUREIRO, C. F. B; CUNHA, C. C. Educação ambiental e gestão participativa de unidades de conservação: elementos para se pensar a sustentabilidade democrática. Ambiente \& Sociedade, v. XI, n. 2. jul/dez, 2008. p. 237$253 . \quad$ https://doi.org/10.1590/S1414753X2008000200003

LÜCHMANN, L. H. H. Associações, participação e representação: combinações e tensões. Lua Nova. São Paulo, n. 84, 2011. p. 353-364. https://doi.org/10.1590/S010264452011000300006

MACHADO, C. J. S; COSTA, D. R. T. R; VILANI, R. M. A análise do princípio de participação social na organização federal dos conselhos gestores de unidades de conservação e mosaicos: realidade e desafios. Revista Brasileira de Gestão e Desenvolviment Regional. v. 8, n. 3, set/dez, 2012. p. 50-75. Disponível em: http://rbgdr.net/revista/index.php/rbgdr/articl e/viewFile/782/300. Acesso em 12 de janeiro de 2019.

MAGNO, L; SIQUEIRA, L. P. G. de; DELESPOSTE, A. G. "Mineração? Aqui não!": a construção da resistência à mineração de bauxita na Serra do Brigadeiro, Minas Gerais. Anais do VIII Simpósio Internacional de Geografia Agrária, Curitiba-PR, 2017. Disponível em: https://www.researchgate.net/profile/Lucas_M agno/publication/325273204_MINERACAO_A QUI_NAO_a_construcao_da_resistencia_a_mi neracao_de_bauxita_na_Serra_do_Brigadeiro _Minas_Gerais_1/links/5b031647a6fdccf9e4f7 630d/MINERACAO-AQUI-NAO-a-construcaoda-resistencia-a-mineracao-de-bauxita-naSerra-do-Brigadeiro-Minas-Gerais-1.pdf. Acesso em 20 de janeiro de 2019.

MILANEZ, B et al. A estratégia corporativa da Vale S.A.: um modelo analítico para Redes Globais Extrativas. Versos - Textos para discussão. PoEMAS, v. 2, n 2, 2018. https://doi.org/10.1590/0102-311x00051219

MILANEZ, B. et al. Minas não há mais: avaliação dos aspectos econômicos e institucionais do desastre da Vale na bacia do rio Paraopeba. Versos - Textos para Discussão. PoEMAS, v. 3, $\mathrm{n}^{\mathrm{o}}$ 1, 2019. Disponível em: http://www.ufjf.br/poemas/files/2017/04/Milan ez-2019-Minas-n\%C3\%A3o-h\%C3\%A1-maisversos.pdf. Acesso em Nov 12, 2019.

MILANEZ, B; MAGNO, L; PINTO; R. G. Da política fraca à política privada: o papel do setor mineral nas mudanças da política ambiental em Minas Gerais, Brasil. Cadernos de Saúde Pública. V.35, n5, Rio de Janeiro, Maio, 2019. Disponível em: http:/cadernos.ensp.fiocruz.br/csp/artigo/735/ da-poltica-fraca-poltica-privada-o-papel-dosetor-mineral-nas-mudanas-da-polticaambiental-em-minas-gerais-brasil. Acesso em 12 de novembro de 2019.

MINAS GERAIS. Decreto 38.319, 27 de setembro de 1996. Cria o Parque Estadual da Serra do Brigadeiro, localizado na Zona da Mata mineira. Diário do Poder Executivo, Belo Horizonte, 28 de setembro de 1996. Disponível em: http://www.siam.mg.gov.br/sla/download.pdf?i $\mathrm{dNorma}=1441$. Acesso em 20 de janeiro de 2019.

MINAS GERAIS. Instituto Estadual de Florestas. Portaria $n^{\circ} 021$, de 17 de fevereiro de 2004. Dispõe sobre as atribuições e composição do Conselho Consultivo do Parque Estadual da Serra do Brigadeiro. Diário do Poder Executivo, Belo Horizonte, 18 de feveriro de 2004. Disponível em: https://sogi8.sogi.com.br/Arquivo/Modulo113. 
MRID109/Registro2397/documento\%201.pdf.

Acesso em 20 de janeiro de 2019.

MINAS GERAIS. Instituto Estadual de Florestas. Portaria $\mathrm{n}^{\mathrm{o}} 53$, de 28 de abril de 2015. Aprova o Regimento Interno do Conselho Consultivo do Parque Estadual da Serra do Brigadeiro. Diário do Poder Executivo, Belo Horizonte, 29 de abril de 2015.

MINAS GERAIS. Secretaria de Meio Ambiente e Desenvolvimento Sustentável. Instituto Estadual de Florestas. Edital de convocação IEF/ERMata $n^{\circ}$ 01/2016. Estabelece regras para a eleição de representantes de órgãos/Entidades Públicas e representantes da sociedade civil organizada, visando compor o Conselho Consultivo do Parque Estadual da Serra do Brigadeiro. 2016a.

MINAS GERAIS, Instituto Estadual de Florestas. Portaria 99, de 16 de dezembro de 2016. Dispõe sobre a composição do Conselho Consultivo do Parque Estadual da Serra do Brigadeiro para o biênio 2016-2018, 2016b.

OLIVEIRA, F. R. C. Missionários e católicos leigos de comunidades rurais: problematizando estratégias de comunicação. In: CRUZ, I. M. N. F. da; ZANGELMI, A. J; HENRIQUES, A. B. (Orgs.). Entre menosprezo, aversão e esquecimento: religiosidades, movimentos sociais e ecologia na Zona da Mata Mineira. Juiz de Fora-MG: Editar Editora Associada, 2015. p. 119-148.

PRAÇA, H. L. F. Unidade de conservação como território e territorialização: aspectos políticos da transformação cultural no meio rural. Geografares, n. 8, 2010. p. 1-20. https://doi.org/10.7147/GEO8.1291

SILVA, C. H. da. Conflitos ambientais no entorno do Parque Estadual da Serra do Brigadeiro (PESB): agricultura familiar e mineração de bauxita. Dissertação (Mestrado em Extensão Rural), $164 f$. Universidade Federal de Viçosa, Viçosa-MG, 2012.

TATAGIBA, L. Os Conselhos Gestores e a democratização das políticas públicas no Brasil. DAGNINO, E. (org.) Sociedade civil e espaços públicos no Brasil. Paz e Terra: São Paulo, 2002. p. 47-103. 